\title{
An Incentive Scheme to Increase Female Access to and Completion of Basic Education in the Democratic Republic of the Congo
}

\author{
Noel A. Ihebuzor \\ Development and Educational Consultant, Abuja, Nigeria \\ Email: naihebuzor@live.com, noel.ihebuzor@gmail.com \\ Received 25 July 2014; revised 18 September 2014; accepted 21 October 2014 \\ Copyright (C) 2014 by author and OALib. \\ This work is licensed under the Creative Commons Attribution International License (CC BY). \\ http://creativecommons.org/licenses/by/4.0/

\section{(c) (i) Open Access}

\begin{abstract}
Policy reforms in education have considerable potential to correct social inequities and assist in the building of more inclusive societies either through improved efficiencies and/or equity in education service provision. Primary education is a public service whose consumption has huge positive externalities-social and economic benefits. In many developing countries, girls are usually excluded from the consumption of this service for a variety of reasons-some of which are social, cultural or economic. The article describes and justifies a reform initiative conceived to increase female access to primary education in the Democratic Republic of Congo (DRC) and sketches an incentive scheme, whose purpose is to improve teacher commitment and improve learning outcomes, for its implementation. The reform measure being proposed, specific egalitarianism (a progenitor of modern-day social transfer schemes) is argued to be robust enough to ensure that girls who are usually the most excluded ones from primary education in the Democratic Republic of Congo (DRC) are enable to access this service as a way of addressing gender equity issues. This type of social transfer (social benefit) strategy when coupled with an incentive scheme that rewards teachers for productivity would yield the socially desirable/beneficial outcome of more girls' enrolling and completing primary education.
\end{abstract}

\section{Keywords}

Social Benefits, Girls Education, Specific Egalitarianism, Conditional Cash Transfers, Incentive Schemes, Performance Measures

Subject Areas: Education, Sociology

\section{The Context of Primary Education in the DRC}

All the indicators for primary education in the Democratic Republic of Congo (DRC) are indicative of an educa-

How to cite this paper: Ihebuzor, N.A. (2014) An Incentive Scheme to Increase Female Access to and Completion of Basic Education in the Democratic Republic of the Congo. Open Access Library Journal, 1: e1023.

http://dx.doi.org/10.4236/oalib.1101023 
tional system in distress-low enrolment and completion rates, low quality of learning, poor teacher quality, unsatisfactory working conditions of teachers, irregular teachers' salaries, inadequate instructional materials and rapidly deteriorating school infrastructure. Gross Enrolment Rate is low, with more boys than girls' registering and completing basic education. Less than 6 out of every 10 school-aged Congolese children are enrolled in primary education. Less than 3 out of 10 girls complete primary education [1]. The reasons for girls' low participation in primary education are cultural and economic as poor parents prefer to withdraw their daughters from school as part of their coping strategies given dominant male child preferences. The gender parity index is thus low. Teachers' commitment, motivation and pedagogical skills show considerable gaps and absenteeism is high. In class, actual time spent on teaching tasks is low. The net result of all the foregoing includes high drop-out rates, high repetition rates, low completion rates (especially for girls) and low levels of academic achievement, all of which are indicative of a high degree of internal inefficiency of the educational the system. The final outcome is a continued inter-generational transmission of female illiteracy with all its negative externalities. All of the above mean that Millennium Development Goals $2 \& 3$ which deal with access to education and gender parity may be difficult to attain for the DRC.

Education is fee-paying and these fees exclude poor children, especially the rural poor and girls. About $70 \%$ of public primary schools are run by religious groups (Catholics, Anglicans, Muslims, Kimbaguistes), all of whom charge fees to cover overheads, salaries and other operational costs. Furthermore, school heads resort to charging fees at school level, which go to paying/topping up teachers' salaries. Though the constitution of the DRC stipulates that primary education is free and compulsory, state fragility has meant an inability to enforce these provisions, a fragility that is worsened by weaknesses of fiscal policy and maladministration. An interesting model of multiple principals and agents operates in the management of primary education in the DRC. In 1977, the state signed a convention with faith based organizations (FBOs) in which it handed over the running primary schools to these whilst retaining control of teachers' payroll. Whilst these FBOs were agents on one hand, they were also principals on the other hand. As agents, they exploited the convention, since it had all the elements of an incomplete contract, to source funds to extend and finance their evangelization. However, they were also principals with the teachers (agents) who taught in schools under their respective jurisdictions and with whom they were either in conflict over salaries on one hand or in complicity in charging fees on the other hand. The communities and parents were also principals but with very limited voice and power, and found themselves constantly exploited in this principal agent problem that usually degenerated to crass predation of weak stakeholders - the parents and their children. According to one source [2], the DRC may be at the head of the unenviable league of countries that charge the highest number of fees at primary schools [2], with school heads and religious organizations showing extreme but deviant creativity in coming up with new fees to line their pockets, apparently oblivious of the severe negative effects of these practices on children's access to education. The UNICEF study revealed the following among others- - Households finance almost the entire cost of education; Household financing of education is compulsory; School fees barely contribute to the quality of education; School fees have developed into a strongly decentralized (local) tax system; Fee management is opaque and strong suspicion prevails on misuse of funds; Financial monitoring of fees or independent control mechanisms do not exist; Households (sole "taxpayers") are marginalized and voiceless" [2]. A situation such as the one described above demands some reform, given pronounced market failure in ensuring access and equity to basic education. The case for reform in such a situation assumes further urgency in the light of global commitments to attaining the goals of Education for All as well as those of MDGs 2 and 3. The next section makes a case for public funding of this sector if access to primary education is to be assured for a large number of Congolese children. The intervention to be proposed is that this paper is one that would ensure that girls in the DRC get access to quality basic education. The proposed scheme thus derives its social justification and importance from the known multiplier benefits and positive externalities that girls' education confers on any society.

\section{The Conceptual Underpinning of the Proposed Pupil Social Transfer and Teacher Incentive Package Schemes}

The previous section brought to fore issues on equity in access to a public service, education. It shows how in the absence of government intervention, the forces of the market - supply and demand are interacting to exclude a considerable number of children from Education. This case of market failure- the inability of the market to efficiently and equitably achieve resource allocation and access to a public service in such a manner to carry on 
board legitimate concerns for equity, justify a case for public funding for this sector [3]. Whenever markets fail in allowing access to public goods, and unregulated markets have been known to under-provide public goods, governments must intervene in the interest of social equity and inclusiveness. Stiglitz has convincingly argued this point of view [3]. In such situations, a government driven allocative mechanism that ensures access to education as a public service and as a right is therefore required. As has been stated, the market is unable to achieve optimal and inclusive allocations of public goods in a manner that reflect concerns for egalitarianism. Yet, we are informed by literature [4] that the consumption of such services results in personal and collective benefits and positive externalities. Allowing the market to apply for such goods is fraught with very dangerous socio-economic consequences and negative externalities including loss of human potential and social cleavages. Access to such basic services thus needs to be publicly funded.

Arguments for funding primary education are moral, social, economic and political. The moral arguments focus on fairness and the right to all the opening of minds that education offers. Social arguments focus on the social benefits that education confers these include increases in social capital, greater social cohesion and social harmony which results when people are educated. Political justifications deal with gains in political stability, such political stability then creating the enabling environment for socially beneficial activities. Economists may not be too impressed with all the foregoing arguments, hence the need for economic justifications which focus on the links between investments in education and the growth of human capital and productivity which have high rates of private and social returns on investment. These returns accrue because of the benefits of an educated populationthese include better management of resources, improved literacy and numeracy, improved health status and improved fertility management. Such benefits are described as positive externalities - the phenomenon where one action somewhere confers benefits elsewhere [3], and there is a growing literature on the positive externalities of education. A reference [5] for example, has shown the positive externality and high social returns to education for indigenous Australians-improved nutrition, better living conditions, lower of criminality, and conclude on the high private and social rate of return. Other externalities include cultural/social cohesion and enhanced productivity [3].

In the section on the education context in the DRC, it was shown that that fees and the actions of agents were acting to exclude more children basic education. Exclusion affects girls more because of cultural practices and preferences. Fees are therefore acting selectively against the girl child. Equity demands that some intervention to reverse this is put in place to address the education needs of girls because of positive externality of female education on literacy, female participation, improved fertility management, improved management of household resources, improved nutritional status of children and other economic benefits. In a study on the costs of sending children to school, a research [6] shows that whereas poor parents may be willing to send their children to school, actual ability to pay often means sacrifices, coping strategies and trade-offs, some of which include skipping food, selling household assets and limiting the number of children who they send to school. This last strategy is usually gendered and girls are most adversely affected as they are the ones usually withdrawn from school when such hard choices have to be made. This underscores the need for special targeting of girls as a way to address this cultural and poverty induced female vulnerability. In making a case for free access to basic education for girls, one is thus making a case for targeting the most vulnerable, arguing the need for priority to be given the worst off and the most excluded and ensuring them access to a decent minimum standard. The special case being made for targeting girls for free access to basic education thus derives from an equity concern. It also draws its raison d'etre from the attested positive externalities of that accrue to societies from girl-child participation in primary education [3]-[5].

The principle we want to propose is that of specific egalitarianism but to be implemented in a manner that recognizes the needs/knavishness of the services providers-the teachers which appears robust enough to address this problem. According to Tobin, specific egalitarianism is based on "the view that certain specific scarce commodities should be distributed less unequally than the ability to pay for them" [7]. It is different from general egalitarianism which involves attempts to redistribute income as a way to reduce inequalities in wealth. General egalitarianism is premised on the freedom and liberty of the beneficiary to do as he/she pleases with the new income and in a way could be said to be less paternalistic than specific egalitarianism which is a more directive way of ensuring that all in society have access to a decent minimum of services which are deemed essential, crucial and fundamental — such as health and education. Specific egalitarianism is thus the un-recognized progenitor of modern day conditional cash transfer system that link benefitting from government social transfer schemes to participation in such vital programs as health, nutrition, education etc. There is now abundant litera- 
ture on the benefits of specific egalitarianist/conditional cash transfer schemes on access to health and education services [8] and [9]. In a number of countries, specific egalitarianism measures such as conditional cash transfers have had a robust effect in increasing demand and access to basic education, but such increases in demand have also often meant a drop in quality of education due to school supply and quality inputs not keeping pace with increased demand and access World Bank [10]. Clearly, another intervention, of a corrective type, capable of checking and correcting undesirable drops in quality inputs to the educational system is needed. In fact, the intervention should be such that when coupled the demand increasing intervention would also boost supply of quality inputs, thereby producing a new and satisfactory equilibrium in the educational system. The next section describes an incentive scheme that would ensure that teachers come to school and do actually teach.

\section{Merging Free Education for Girls with an Incentive Scheme to Improve Teacher Motivation through a Rewards System}

We have argued for an equity intervention that would ensure access for girls. More than this however, it is also important to put in place measures that would ensure that girls then stay on in school and are actually taught by teachers. It is now common knowledge from empirical studies that teacher absence, poor quality teaching and girls drop out are rife in schools in developing economies [11] [12] and unless checked have the potential to frustrate the realization of the benefits of the proposed specific egalitarian measure. The proposed reform is free access for girls through a voucher system accompanied by and coupled with to a teacher performance pay system that ties teachers' pay to enrolment, transition and completion rates for children, especially girls as well as to performance in the end of primary school examinations. Schools that admit girls receive vouchers which are redeemed with funds from government. These funds are then used to complement teachers' salaries. Schools where girls stay on are rewarded through a performance point based system. Schools where girls stay and achieve a certain level of pass receive additional bonuses. The aim of the proposed reform is to increase girls' access, transition, completion and passes rates. The expected result is that more girls are successfully completing primary education and applying the knowledge and skills gained therein for personal and social benefits.

Specifically, the performance related incentives for the scheme will be the following:

- Schools are funded on the basis of number of girls they enroll;

- Additional incentives are paid on the basis of number of girls who transit to the next class each year;

- Additional incentives to schools on the number of girls who succeed in TENAFEP (testes de find etudes primaries);

- Additional incentives are paid to schools where teachers' attendance meets a threshold.

One advantage of the proposed incentive scheme is the increased competition among schools to go out there and attract and retain children, especially girls—schools therefore are encouraged by the incentive scheme to undertake enrolment drives at no extra cost to government. Another benefit is increased commitment of teachers to teach well given benefits associated with pass rates at the end of primary school examinations. Finally, by also tying incentives and rewards to number of girls who transit to the next higher grade, the reform will have the effect of keeping more girls in school. The literature on performance pay presents evidence that justify confidence that our proposed reform will have the effects we have suggested and the next section examines that growing literature as well as some it challenges [13]-[15].

Pay for performance has its origins in the private sector though attempts are now being made to apply it to management in the public service. Views of its relevance and efficacy for the public service are mixed and evidence for it inconclusive. A lot depends on the adequacy of measurement and the motivation and response of the human agent. Smith observes that performance measurements reflect an attempt to apply managerial cybernetics in the control of human beings but could fail because reflecting humans can decipher the intentions of the control and act to defeat them, and thus distort the reliability of the measurement. Performance measurement in the public service is also subjective and evidence of the effect of rewards on performance is inconclusive. Administration of rewards can also be politicized [13]-[15].

Evidence, albeit inconclusive, exist of relationships between incentives and outcomes in teaching [15]. Available studies have evidence which link teachers' productivity to financial rewards, though studies in this area have been marred by selectivity and limited sample size which undermine confidence in generalizations and extrapolations from them. The effectiveness of incentives schemes have also been shown to be related to the manner in which performance has been measured, with indications of positive links between good performance 
measures and productivity improvement [14] and [16]. Poor measures weaken the efficacy of incentive schemes, and all of this because of the agent's tendency to "play" the system. As a general principle, the sharper the measure and the greater the minimization/control of "noise", (noise referring to those extraneous variables which may interfere with the measurement of the agents behavior under study), the higher is the power and effect of an incentive. One source [16] also shows that randomness and unpredictability of measurement/inspection systems increased the power of the incentives in health service delivery. Such a view agrees with findings from a study in education [17] that a combination of monitoring and financial incentives can reduce teacher absence and improve children's learning.

But performance for pay is not without its risks and the literature identifies such risks [18]. These include perverse incentives, loss of public confidence and distortions in the discharge of their functions. Smith identification of some of the eight unintended consequences of performance measurement is also instructive in which it shows how human agents can act to frustrate the intentions of those who wish to control them. Problems of performance measurement include tunnel vision (focus on the countable), sub-optimization (focus on narrow local objectives at the expense of broader ones), myopia (short sightedness and short-termism), measure fixation (activities focus on reported measures), misrepresentation (cheating), misinterpretation (reading the info wrongly), gaming (keeping targets low) and ossification. All eight are the result of a lack of congruence between the goals of the agent — as moderated by the implicit reward scheme — and the actual goals of the principal. In the first three, the lack of congruence arises because of a divergence between organizational objectives and the measurement scheme. Measure fixation and misrepresentation result from an inability to measure complex phenomena with precision or fidelity. Misinterpretation; gaming reflects an inability on the part of the controller to process performance data correctly, while ossification indicates an inability to respond to new circumstances. [17] [19] [20].

Being aware of these numerous challenges, the teacher incentive scheme thus proposes to address problems teacher absence through a system of irregular but constant monitoring of teacher presence. The association of parents (COPAs) will do checks on teacher attendance and report back. School registers will be monitored as these show pupil presence and indirectly teacher presence. As also stated earlier, the scheme also proposes to tie teachers' rewards to the pass rates of their pupils. In doing this, the scheme will be using the reward system to ensure that teachers actually teach though this runs the risk of making teachers to teach pupils to pass the external examinations and not to teach for learning. And the point is worth making that Performance measures for P4P in teaching must be structured to capture the multi-dimensionality of teaching and thus focus not just on academic achievement but also on social development, moral values and interpersonal skills. The proposed scheme does not address the last three and this is a weakness and readers should bear this limitation in mind when trying to implement the proposed scheme.

We are also aware that whereas pass rate in an external examination is a perfectly observable measure, it is on its own an imperfect indicator of the effort of the agent (the teacher). However by linking rewards to teacher attendance and transition rates in school, we hope to have come up with an incentive scheme that compensates for the use of this proxy whose reliability is impacted by other extraneous variables. Some care is also required in applying this incentive. Good incentive regimes encourage effort but are not so aggressive as to impose penalties for failures for reasons outside the agent's control [21]. In good incentive schemes, the links between effort and incentive should be clear. We recommend team based incentives since their benefits far outweigh the dangers posed by free riders in team based incentives. Individual based incentives lower morale and ultimately depress productivity [15]. Team based schemes also have the advantage that they oblige team members to monitor, and hopefully mentor, each other [14].

\section{Challenges Posed by the Proposed Reform Package}

UNESCO [22] shows that incentive schemes for girls' participation in primary education work, but that their chances of success are higher where they satisfy three conditions-there is coordination and cooperation among its component parts, there is community involvement and lasts for at least one primary life cycle and if they include strategies for overcoming socio-cultural barriers to girl education. Another research [11] makes a case for beneficiary control over service providers but are quick to point out some the problems associated with it especially transactions costs and power asymmetry.

The suggested reform poses two important funding challenges_-expansion of fiscal space to pay for the pro- 
posed free access for girls and changes in percentage allocations across sectors of the national budget. For issues of fiscal space, it is good to remind ourselves that states have mechanisms for increasing their fiscal space. These include tax and non-tax revenues, domestic and external borrowing as well as pursuing more fiscal discipline. A recent survey of the DRC by the World Bank [23] reveals considerable gaps in these areas of expanding fiscal space and inculcating fiscal discipline. But it also revealed important opportunities for major improvements. These improvements should yield the funds to pay for free tuition for girls at the primary level. On the issue of implications for inter-sectoral budget allocations, it is worth noting that the central issues of economics are scarcity, choice and opportunity costs, and this applies to public sector economics (PSE) with its concerns for regulatory, distributional and allocative efficiencies as well as equity. PSE is thus about calculated and intelligent risks, of scales of preference and evaluating alternatives. PSE also looks at wider social issues beyond financially countable gains. It also looks at social efficiency and benefits albeit in a long term perspectives since it knows that a certain level of social inclusiveness and equity is necessary for societies to function effectively. In weighing up funding options across sectors, it is important to remind ourselves that some decisions may have consequences and externalities for the present and the future, some of which may be difficult to reverse. Given the advantages of a literate female population on other sectors of the economy - health, nutrition, environment, population, increased budgetary allocations in this sector has a considerable potential to catalyze developments in all these other sectors. The case here is one on cost benefit analysis of different sector budget allocation scenarios. The dangers of shorttermism, maturity time on returns on investment and immediate visibility as drivers of decisions for budget allocations for social transfer purposes is real but these will need to be tempered by a deeper economic analysis which focuses on long term gains and wider socially sustainable impacts. With such a mind set, girls' education would be first call. The following economic concepts—opportunity cost, externality (negative and positive), equity, specific egalitarianism, incentives and transactions costs will be used in developing the case made in this essay, though it is useful to agree with Lamont and Favor (2007) [24] and remind ourselves that in matters of distributive justice such as is the case in access to basic education, economics alone is not sufficient to decide policy choices.

\section{Conclusion}

This essay has examined how the combined use of specific egalitarian measure involving a conditional cash transfer scheme for girls and a teacher reward scheme involving a pay for performance scheme could be used to increase female participation and successful completion of basic education in the DRC. The essay also sketched out in broad lines how such a scheme could be implemented. In the process of sketching out the implementation arrangements, the essay also discusses some of the risks inherent in performance-based incentive scheme when applied to teachers, the most critical of which is that teachers would focus all their energies on getting their wards to pass the examination in question with the danger that other vital cognitive, moral, socio-affective and interpersonal components of education are neglected. This would be unfortunate where it is to happen. This paper would then wish to end by reminding educational practitioners and policy reform experts that in their efforts to use incentives and social transfer schemes to boost educational access and quality, they do not wind up creating perverse incentives whose long-term effects would be to undermine the emergence of wholesome and rounded education which involves psycho-motor, affective and cognitive development of learners.

\section{References}

[1] UNICEF/RDC (2001) Enquete nationale sur la situation des enfants et des femmes. MICS2, Multiple Indicator Cluster Study, UNICEF/USAID, Kinshasa.

[2] UNICEF (2007) School Fee Practice and Policy in the DRC—Frais de fonctionnementoufonds de famille. UNIICEF, DRC, Kinshasa.

[3] Stiglitz, J.E. (2000) Economics of the Public Sector. Norton, New York.

[4] Besley, T. and Ghatak, M. (2003) Incentives, Choice, and Accountability in the Provision of Public Services. Oxford Review of Economic Policy, 19, 235-249. http://dx.doi.org/10.1093/oxrep/19.2.235

[5] Junankar, P.N. and Liu, J. (2003) Estimating the Social Rate of Return to Education for Indigenous Australians. Education Economics, 11, 169-192.

[6] Boyle, S., Brock, A., Mace, J. and Sibbons, M. (2002) Reaching the Poor-The Costs of Sending Children to School. 
DFID, London.

[7] Tobin, J. (1970) On Limiting the Domain of Inequality. Journal of Law and Economics, 13, 263-277. http://dx.doi.org/10.1086/466693

[8] DFID (2011) Cash Transfers Literature Review. DFID/UKaid, London, UK.

[9] World Bank (2004) Cost, Financing and School Effectiveness in Malawi: A future of Limited Choice and Endless Opportunities. Working Paper 78, Washington DC.

[10] World Bank (2005) Mozambique Poverty and Social Impact Analysis: Primary School Enrolment and Retention—The Impact of School Fees. Report No. 29423-MZ, The World Bank, Washington, DC.

[11] Banerjee, A. and Duflo, E. (2006) Addressing Absence. Journal of Economic Perspectives, 20, 117-132. http://dx.doi.org/10.1257/089533006776526139

[12] Chaudhury, N., Hammer, J., Kremer, M., Muralidharan, K. and Roger, F.H. (2006) Missing in Action, Teacher and Health Worker Absence in Developing Countries. Journal of Economic Perspectives, 20, 91-116. http://dx.doi.org/10.1257/089533006776526058

[13] Courty, P. and Marschke, G. (2003) Dynamics of Performance-Measurement Systems. Oxford Review of Economic Policy, 19, 268-284. http://dx.doi.org/10.1093/oxrep/19.2.268

[14] Burgess, S. and Ratto, M. (2003) The Role of Incentives in the Public Sector: Issue and Evidence. Oxford Review of Economic Policy, 19, 285-300. http://dx.doi.org/10.1093/oxrep/19.2.285

[15] Prentice, G., Burgess, S. and Propper, C. (2007) Performance Pay in the Public Sector: A Review of the Issues and Evidence.

[16] Bevan, G. and Hood, C. (2006) What's Measured Is What Matters: Targets and Gaming in the English Public Health Care, System. Public Administration, 84, 517-538. http://dx.doi.org/10.1111/j.1467-9299.2006.00600.x

[17] Duflo, E., Hanna, R. and Ryan, S. (2008) Monitoring Works: Getting Teachers to Come to School. Centre for Economic Policy Research, Massachusetts.

[18] Hood, C. (2007) Public Service Management by Numbers: Why Does It Vary? Where Has It Come from? What Are the Gaps and the Puzzles? Public Money and Management, 27, 95-102. http://dx.doi.org/10.1111/j.1467-9302.2007.00564.x

[19] Propper, C. and Wilson, D. (2003) The Use and Usefulness of Performance Measures in the Public Sector. Oxford Review of Economic Policy, 19, 250-267. http://dx.doi.org/10.1093/oxrep/19.2.250

[20] Smith, P. (1995) On the Unintended Consequences of Publishing Performance Data in the Public Sector. International Journal of Public Administration, 18, 277-310. http://dx.doi.org/10.1080/01900699508525011

[21] Grout, P.A. and Stevens, M. (2003) The Assessment: Financing and Managing Public Services. Oxford Review of Economic Policy, 19, 215-234. http://dx.doi.org/10.1093/oxrep/19.2.215

[22] UNESCO (2000) Incentive Schemes for Promoting Girls Education in Pakistan. UNESCO Pakistan

[23] World Bank (2008) Democratic Republic of Congo Economic Report. Fall 2008, World Bank, Washington and Kinshasa.

[24] Lamont, J. and Favor, F. (2007) Distributive Justice. Stanford Encyclopedia of Philosophy. http://plato.stanford.edu/entries/justice-distributive/ 